\title{
Study To Determine The Knowledge And Practices Regarding Prevention Of Dengue Fever Among The Junior Health Workers (Jhw's) Working In The Phe's Of Belgaum Taluka.
}

\author{
Nandkumar R. Kakade \\ Lecturer, Dept. of Community Health Nursing Krishna Institute of Nursing Sciences, KIMSDU, Karad.
}

\begin{abstract}
Research Question:-What is the level of knowledge \& practices regarding prevention of Dengue fever among the JHWs?

Objectives of the Study were: -

1. To assess the knowledge of JHWs regarding cause, spread and prevention of dengue fever.

2. To identify the practices towards preventive measures in dengue fever among the JHWs.

3. To find out the association between the sociodemographic variables of JHW's And level of knowledge regarding dengue.

4. To find out the association between knowledge and practices towards Prevention of dengue fever among the JHWs.
\end{abstract}

Participants:

Purposely selected 95 JHWs between 19-58yrs age group of both sex working under the PHC's of Belgaum Taluka.

Study Setting: Results:

Community based. The study was conducted in all the 12 Primary Health Centers of Belgaum Taluka.

It was evident that maximum number of JHW's had average knowledge and average practices about Dengue prevention. There is no significant association between the sociodemographic variables of JHW's and level of knowledge regarding dengue.

There is no significant association between knowledge regarding dengue \& practices towards dengue prevention.

Conclusion:

Maximum no of J.H.W's had their education up to P.U.C. I, which is not sufficient in preventing \& controlling dengue even they don't have any special training on dengue but still average no. of J.H.W's have average knowledge. This inadequate knowledge may not be helpful in preventing \& controlling dengue.

I. Introduction:-

Health has been declared as a fundamental human right. While National governments all over the world are striving to expand and improve their health care service to overcome a continuous threat from emergence \& resurgence vector borne diseases. ${ }^{1}$

Dengue fever is one of the most crucial emerging diseases of the tropical and sub-tropical regions, affecting urban and periurban areas. Rapid population growth, expanding urbanization, inadequate municipal water supply and difficulties in liquid waste disposal are the main factors that lead to an abundance of new breeding sites for mosquito vectors. The resurgence of dengue fever has become worrisome. ${ }^{2}$

WHO reports, all over world there are 50 million cases and about 2,400 dengue deaths every year. In India, the first reported outbreak of dengue fever took place in Kolkata (then Calcutta) in 1824. In modern times, the first epidemic of Dengue fever occurred in Delhi in 1966, and then up to 2003, there was several cases of Dengue were reported. In October 2003 following good monsoon in the country, more than 7,000 were affected and more than 2001 died. The states with large number of cases were Kerala, Uttar Pradesh, Delhi, Rajasthan, West Bengal, Karnataka, and Maharashtra. ${ }^{3}$

Dengue viral infections are significant cause of morbidity and mortality in many parts of the world, including India. According to available information, dengue is very life threatening disease. As there is no specific vaccine and specific treatment for dengue infection, only the preventive measures are the important, and it is the duty of health care providers to teach communities regarding prevention aspects. Since JHWs are the effective 'Change Agent' at grass roots level in creating awareness and understanding the risk of dengue fever. It is necessary to assess the knowledge and preventive practices of these category workers to find out whether they are properly equipped with these aspects. Hence the study undertaken. ${ }^{4,5,6}$ 


\section{Material \&Methods:}

The study was conducted on 95 JHW's who are passed the routine course of JHW's are selected as samples. The purposive, non-probability sampling technique was applied to select the subjects for the study. Descriptive survey approach was applied. Structured questionnaire was prepared as a tool. The tool had 44 items of MCQ type was organized into two main sections. Section I contains Sociodemographic variables of JHW's. Section II contains Part A : 29(65.90\%) items were on Knowledge of JHW's regarding meaning, signs \& symptoms, cause, spread and prevention of Dengue fever. While remaining $15(34.10 \%)$ items were on Part B: i.e. on knowledge of practices regarding dengue. Scoring pattern adopted was ' 1 ' mark for a correct answer and ' 0 ' for wrong answer. The knowledge \& practices were scored by giving Grades such as Poor, Average, Good after computing Mean \& Standard Deviation (S.D.)

Scoring Procedure: Poor: <Mean-1S.D.

Average: Mean \pm 1S.D.

Good: Mean + 1S.D.

\section{Results \& Discussion:}

A total 95 JHW's were assessed for their knowledge \& practices regarding dengue fever with the help of structured questionnaire. It was observed that the knowledge regarding dengue for mean (15.89) and median (16) whereas the practices regarding dengue for mean (7.83) and median (8) which represents the following table-

Table No. 1

Distribution of the JHW's according to sociodemographic variables.

$\mathrm{N}=95$

\begin{tabular}{|c|c|c|c|}
\hline Sr. No. & Variables & Frequency & Percentage \\
\hline \multirow[t]{5}{*}{1} & Age (Yrs) & & \\
\hline & $19-28$ & 20 & 20 \\
\hline & $29-38$ & 17 & 17.9 \\
\hline & $39-48$ & 26 & 27.3 \\
\hline & $49-58$ & 32 & 33.7 \\
\hline \multirow[t]{3}{*}{2} & Sex & & \\
\hline & Male & 24 & 25.2 \\
\hline & Female & 71 & 74.8 \\
\hline \multirow[t]{4}{*}{3} & Educational status & & \\
\hline & PUC-I & 51 & 53.7 \\
\hline & PUC-II & 34 & 35.8 \\
\hline & Graduation & 10 & 10.5 \\
\hline \multirow[t]{3}{*}{4} & Training on dengue programme & & \\
\hline & Had & 00 & 00 \\
\hline & Did not have & 95 & 100 \\
\hline \multirow[t]{4}{*}{5} & Experience (Yrs) & & \\
\hline & $<5$ & 29 & 30.5 \\
\hline & $6-10$ & 04 & 4.2 \\
\hline & $>10$ & 62 & 65.2 \\
\hline
\end{tabular}

The data presented in table no. 1 revealed that majority of JHW's 32(33.7\%) were in the age group of 4958 years and only $17(17.9 \%)$ were in the age group of $29-38$ years. Maximum JHW's $74.8 \%$ were females. Most of the JHW's 51(53.7\%) had education upto PUC-I. 10 (10.5\%) had completed graduation, and $62(65.2 \%)$ had more than 10 years of experience. One significant thing observed that nobody had undergone any special training on dengue.

Table No. 2

Distribution of the subjects according to mean, median, mode, standard deviation and range of knowledge score regarding dengue-

\begin{tabular}{|l|c|c|c|c|c|}
\hline \multicolumn{1}{|c|}{ Area of analysis } & Mean & Median & Mode & S.D. & Range \\
\hline Part A (Knowledge regarding dengue) & 15.89 & 16 & 16 & 2.88 & 15 \\
\hline Part B(Practices regarding Dengue) & 7.83 & 8 & 8 & 2.18 & 9 \\
\hline
\end{tabular}


Table No. 3

Area-wise distribution of JHW's according to knowledge regarding Dengue fever

\begin{tabular}{|c|l|c|c|}
\hline \multicolumn{1}{|c|}{ Kr. No. } & \multicolumn{1}{c|}{ Nnowledge particulars regarding Dengue } & $\begin{array}{c}\text { Correct } \\
\text { responses }\end{array}$ & Percentage \\
\hline 1 & Meaning incidence and prevalence & 94 & 98.94 \\
\hline 2 & Cause & 95 & 100 \\
\hline 3 & Spread & 95 & 100 \\
\hline 4 & Signs \& symptoms & 70 & 73.68 \\
\hline 5 & Investigations & 71 & 74.73 \\
\hline 6 & Preventive and control measures & 95 & 100 \\
\hline
\end{tabular}

It was observed that from Part-A, 95(100\%) of JHW's knew about cause, spread, preventive and control measures regarding dengue while in Part-B, only 70(73.68\%) of JHW's were aware about signs and symptoms of dengue. Hence there is wide scope to improve the knowledge of JHW's in this area.

Table No. 4

Distribution of JHW's according to knowledge regarding preventive and control measures for dengue -

$\mathbf{N}=95$

\begin{tabular}{|c|l|c|c|}
\hline Sr. No. & $\begin{array}{l}\text { Knowledge particulars regarding } \\
\text { preventive and control measures for dengue }\end{array}$ & $\begin{array}{c}\text { Correct } \\
\text { responses }\end{array}$ & Percentage \\
\hline 1 & Prevention of complication & 15 & 15.79 \\
\hline 2 & Vaccine & 65 & 68.42 \\
\hline 3 & National programmes and preventive policies & 64 & 67.37 \\
\hline 4 & Treatment modalities & 28 & 29.47 \\
\hline 5 & Vector control measures & 75 & 78.95 \\
\hline
\end{tabular}

It was observed that only $15.79 \%$ of JHW's knew about prevention of complication, $68.42 \%$ of them knew about vaccine, $67.37 \%$ of them knew about National programmes and policies, $29.47 \%$ of them knew about treatment modalities and $78.95 \%$ of JHW's knew about vector control measures. There is wide scope for improvement in the knowledge of JHW's regarding prevention of complications \& Treatment modalities in dengue.

Table No. 5

Distribution of JHW's according to areas of practices regarding Treatment modalities $\mathrm{N}=95$

\begin{tabular}{|c|l|c|c|}
\hline Sr. No. & \multicolumn{1}{|c|}{ Practices regarding treatment modalities } & Correct responses & Percentage \\
\hline 1 & Treating high degree fever & 28 & 29.47 \\
\hline 2 & Prevention of dehydration and shock & 74 & 77.89 \\
\hline 3 & Prevention of gastric complication & 27 & 28.42 \\
\hline
\end{tabular}

Presenting data suggests that (74)77.89\% of JHW's were aware about prevention dehydration and shock (28) $29.47 \%$ of them knew to treat high fever while (27) $28.42 \%$ of them about the prevention of gastric complications.

It is presumed that if JHW's knows Hydrotherapy to treat the high degree fever, not to give Aspirin to prevent further dangers like dehydration, shock \& G.I. bleeding which they can prevent. If JHW's are not having adequate knowledge regarding cardinal signs of Dengue, its various types, clinical investigations \& treatment modalities they cannot provide better preventive services in dengue.

Table No. 6

Distribution of JHW's according to areas of practices regarding vector control measures -

\begin{tabular}{|c|l|c|c|}
\multicolumn{3}{|c}{ vector control measures - } & \multicolumn{2}{c|}{ N=95 } \\
\hline Sr. No. & Practices regarding vector control measures & Correct responses & Percentage \\
\hline 1 & Insecticide sprays & 43 & 44.26 \\
\hline 2 & Spraying operations & 38 & 40 \\
\hline 3 & Treatment mosquito nets & 41 & 43.68 \\
\hline 4 & Destruction of Aedes eggs & 38 & 40 \\
\hline
\end{tabular}


Vector control measures are one of the important strategies in prevention \& control of dengue. In this study it was noticed that $44.26 \%$ of JHW's knew about the insecticide sprays, $40 \%$ of them were aware about spraying operations, $43.68 \%$ of them knew about treatment of mosquito nets, while $40 \%$ of JHW's knew about the destruction of Aedes eggs.

The following table shows the level of knowledge regarding dengue.

Table No. 7

$$
\mathrm{N}=95
$$

\section{Level of knowledge regarding dengue among JHW's -}

\begin{tabular}{|c|l|c|c|}
\hline Sr. No. & \multicolumn{1}{|c|}{ Knowledge } & No. of JHW's & Percentage \\
\hline 1 & Poor & 24 & 25.3 \\
\hline 2 & Average & 53 & 55.8 \\
\hline 3 & Good & 18 & 18.9 \\
\hline & Total & 95 & 100 \\
\hline
\end{tabular}

The above table reveals that 53(55.8\%) of JHWs were having average knowledge and only $18(18.9 \%)$ had good knowledge regarding dengue.

Table No. 8

Level of knowledge about practices regarding prevention of dengue among JHW's $\mathbf{N}=95$

\begin{tabular}{|c|l|c|c|}
\hline Sr. No. & Knowledge about practices & No. of JHW's & Percentage \\
\hline 1 & Poor & 24 & 25.3 \\
\hline 2 & Average & 50 & 52.6 \\
\hline 3 & Good & 21 & 22.1 \\
\hline & Total & 95 & 100 \\
\hline
\end{tabular}

The above table reveals that 50(52.6\%) of JHW's were having average practices and $21(22.1 \%)$ had good practices regarding prevention of dengue.

South East. Asian. J Trop. Med Public Health. 1992 June published in its article that health education efforts in Mac. Sot Gen. Hospital Thailand area could induce the majority of respondents to accept themselves as responsible for the Aedes control program. Health education by health personnel played an important role in disseminating DHF information and prevention methods. ${ }^{7}$

Table No. 9

Association between the knowledge and sociodemographic variables of JHW's.

\begin{tabular}{|c|c|c|c|c|c|c|c|c|c|c|c|}
\hline \multirow{3}{*}{$\begin{array}{c}\text { Sr. } \\
\text { No. }\end{array}$} & \multirow[b]{3}{*}{ Variable } & \multirow{2}{*}{\multicolumn{6}{|c|}{ Level of knowledge }} & \multicolumn{4}{|c|}{$\mathbf{N}=95$} \\
\hline & & & & & & & & \multirow[t]{3}{*}{ Total } & \multirow[t]{3}{*}{ Chisq } & \multirow[t]{3}{*}{ df } & \multirow[t]{3}{*}{$P$ value } \\
\hline & & \multicolumn{2}{|c|}{ Poor } & \multicolumn{2}{|c|}{ Average } & \multicolumn{2}{|c|}{ Good } & & & & \\
\hline \multirow[t]{5}{*}{$\mathrm{I}$} & Age Yrs) & Freq & $\%$ & Freq & $\%$ & Freq & $\%$ & & & & \\
\hline & $19-28$ & 9 & 45 & 8 & 40 & 3 & 15 & 20 & \multirow{4}{*}{12.901} & \multirow{4}{*}{6} & \multirow{4}{*}{0.045} \\
\hline & $29-38$ & 3 & 17.6 & 13 & 76.5 & 1 & 5.9 & 17 & & & \\
\hline & $39-48$ & 2 & 77 & 17 & 65.4 & 7 & 26.9 & 26 & & & \\
\hline & 49 \&above & 10 & 31.3 & 15 & 46.9 & 7 & 21.9 & 32 & & & \\
\hline \multirow[t]{3}{*}{ II } & Sex & & & & & & & & \multirow{3}{*}{0.256} & \multirow{3}{*}{2} & \multirow{3}{*}{0.880} \\
\hline & Female & 17 & 24.3 & 39 & 55.7 & 14 & 20 & 70 & & & \\
\hline & Male & 7 & 28 & 4 & 16 & 14 & 56 & 25 & & & \\
\hline \multirow[t]{4}{*}{ III } & Education & & & & & & & & \multirow{4}{*}{0.955} & \multirow{4}{*}{4} & \multirow{4}{*}{0.917} \\
\hline & PUC-I & 12 & 23.5 & 28 & 54.9 & 11 & 21.6 & 51 & & & \\
\hline & PUC-II & 10 & 29.4 & 19 & 55.9 & 5 & 14.7 & 34 & & & \\
\hline & Graduate & 2 & 20 & 6 & 60 & 2 & 20 & 10 & & & \\
\hline \multirow[t]{4}{*}{ IV } & Experience & & & & & & & & \multirow{4}{*}{2.277} & \multirow{4}{*}{4} & \multirow{4}{*}{0.685} \\
\hline & $<5$ & 9 & 31 & 16 & 55.2 & 4 & 13.8 & 29 & & & \\
\hline & $6-10$ & 2 & 15.4 & 9 & 69.2 & 2 & 15.4 & 13 & & & \\
\hline & 11 \&above & 13 & 24.5 & 28 & 52.8 & 12 & 22.6 & 53 & & & \\
\hline
\end{tabular}

Above table expresses that there is association between the age of JHW's and level of knowledge regarding Dengue at $\mathrm{p}=0.05$ level of significance. 
Table No. 10

Association between the sociodemographic variables and practices regarding dengue prevention of JHW's -

\begin{tabular}{|c|c|c|c|c|c|c|c|c|c|c|c|}
\hline \multirow{3}{*}{$\begin{array}{l}\text { Sr. } \\
\text { No. }\end{array}$} & \multirow{3}{*}{ Variable } & & & & & & & & & & \\
\hline & & \multicolumn{6}{|c|}{ Level of knowledge } & \multirow[t]{3}{*}{ Total } & \multirow[t]{3}{*}{ Chisq } & \multirow[t]{3}{*}{ df } & \multirow{3}{*}{$\begin{array}{c}P \\
\text { value }\end{array}$} \\
\hline & & \multicolumn{2}{|c|}{ Poor } & \multicolumn{2}{|c|}{ Average } & \multicolumn{2}{|c|}{ Good } & & & & \\
\hline \multirow[t]{5}{*}{ I } & Age (Yrs) & Freq & $\%$ & Freq & $\%$ & Freq & $\%$ & & & & \\
\hline & $19-28$ & 2 & 10 & 14 & 70 & 4 & 20 & 20 & \multirow{4}{*}{10.384} & \multirow{4}{*}{6} & \multirow{4}{*}{0.109} \\
\hline & $29-38$ & 8 & 47.1 & 4 & 23.5 & 5 & 29.4 & 17 & & & \\
\hline & $39-48$ & 5 & 19.2 & 16 & 61.5 & 5 & 19.2 & 26 & & & \\
\hline & 49 \&above & 9 & 28.1 & 16 & 50 & 7 & 21.9 & 32 & & & \\
\hline \multirow[t]{3}{*}{ II } & Sex & & & & & & & & \multirow{3}{*}{0.079} & \multirow{3}{*}{2} & \multirow{3}{*}{0.961} \\
\hline & Female & 18 & 25.7 & 37 & 52.9 & 15 & 21.4 & 70 & & & \\
\hline & Male & 6 & 24 & 13 & 52 & 6 & 24 & 25 & & & \\
\hline \multirow[t]{4}{*}{ III } & Education & & & & & & & & \multirow{4}{*}{3.453} & \multirow{4}{*}{4} & \multirow{4}{*}{0.485} \\
\hline & PUC-I & 14 & 27.5 & 29 & 56.9 & 8 & 15.7 & 51 & & & \\
\hline & PUC-II & 7 & 20.6 & 16 & 47.1 & 11 & 32.4 & 34 & & & \\
\hline & Graduate & 3 & 30.0 & 5 & 50.0 & 2 & 20 & 10 & & & \\
\hline \multirow[t]{4}{*}{ IV } & Experience & & & & & & & & \multirow{4}{*}{1.706} & \multirow{4}{*}{4} & \multirow{4}{*}{0.790} \\
\hline & $<5$ & 5 & 17.2 & 17 & 58.6 & 7 & 24.1 & 29 & & & \\
\hline & $6-10$ & 3 & 23.1 & 7 & 53.8 & 3 & 23.1 & 13 & & & \\
\hline & 11 \&above & 16 & 30.2 & 26 & 49.1 & 11 & 20.8 & 53 & & & \\
\hline
\end{tabular}

Above table expresses that there is no statistically significant association between the sociodemographic variables and practices of the JHW's regarding prevention of dengue at $p=0.05$ level of significance.

Table No.11

Association between knowledge and practices -

\begin{tabular}{|c|c|c|c|c|c|c|c|c|}
\hline \multirow{4}{*}{ Sr. No. } & \multirow{4}{*}{ Knowledge } & \multirow{2}{*}{\multicolumn{6}{|c|}{ Practices }} & \multirow{4}{*}{ Total } \\
\hline & & & & & & & & \\
\hline & & \multicolumn{2}{|c|}{ Poor } & \multicolumn{2}{|c|}{ Average } & \multicolumn{2}{|c|}{ Good } & \\
\hline & & Freq & $\%$ & Freq & $\%$ & Freq & $\%$ & \\
\hline 1 & Poor & 8 & 33.3 & 13 & 26 & 3 & 14.3 & 24 \\
\hline 2 & Average & 14 & 58.3 & 29 & 58 & 10 & 47.6 & 53 \\
\hline \multirow[t]{2}{*}{3} & Good & 2 & 8.3 & 8 & 16 & 8 & 08.1 & 18 \\
\hline & Total & 24 & 25.26 & 50 & 52.63 & 21 & 22.11 & 95 \\
\hline
\end{tabular}

Chi-square $=7.674$

$\mathrm{df}=4$

$\mathrm{p}=0.104$

The above table depicts that there is no association between knowledge regarding dengue and practices towards dengue prevention

WHO on World Health Day 2006, developed a theme, "Working together for health". The theme highlights the challenging and inspiriing work done by health workers worldwide. The four areas chosen for action are educating and training health workers, supporting and protecting them; enhancing their effectiveness; and tackling health imbalances and inequities. ${ }^{8}$

To secure an acceptable level of "Health For All" through the implementation of primary health care programmes. JHW's are the main vehicle for the promotion of primary care and the services they provide are more important and appropriate to meet the health needs of the community. An editorial article on Health workers in Health Action mentioned that health workers are the backbone of the health care system. Hence they are also called as backbone of health care services. ${ }^{9}$

\section{Conclusion:}

With the obtained findings the following conclusions are drawn -

- Most of the JHW's 51(53.7\%) had education up to PUC - I , which is not sufficient to undertake complex tasks like prevention \& control of Dengue by adopting advance technologies.

- Maximum number of JHW's 62(65.2\%) had experience of working in the dept. for more than 10 years and maximum of them $32(33.7 \%)$ were above the age of 49 years which indicated that long years of experience and age maturity helps the JHW's to be more responsible towards the tasks of dengue control activities. 
- The majority of JHW's 71 (74.8\%) were females, since majority of the domestic environmental control activities are managed by females at home. The female JHW's would be more influential in implementing prevention and control activities of Dengue.

- None of JHW's had undergone any special training for dengue control. Maximum number of JHW's 53 $(55.8 \%)$ had average knowledge, 18 (18.9\%) had good knowledge while $24(25.3 \%)$ had poor knowledge regarding dengue.

- It was also revealed that maximum number of JHW's 50 (52.6\%) had average practices, while $24(25.3 \%)$ of them had poor practices regarding dengue prevention.

- The $\chi 2$ (Chi-Square) value (7.674) and p value is $<0.05$ showed that there is no association between the knowledge regarding dengue and practices toward it's prevention.

With the help of the above findings it is concluded that there is a strong need to conduct a special training programme pertaining to Dengue control, which will help the JHW's to improve their knowledge towards good practices to be an effective change agents in control and prevention of Dengue fever.

\section{References}

[1] Park K. Text book of preventive and social medicine. $19^{\text {th }}$ ed. Jabalpur. M/s.Banarasidas Bhanot Publishers, Jabalpur, 2007: 28, 206 $-209,534,685$.

[2] Satyanarayan K. Emerging infectious diseases in South East Asia; Research Priorities. ICMR Bulletin 2004. May- June; 34 (5-6): 30

[3] Rao BS. Principles of community Medicine. $4^{\text {th }}$ Ed. New Delhi. AITBS Publications, 2005; $352-355$

[4] Gulani K.K. Community Health Nursing- Principles and Practices. ${ }^{\text {st }}$ ed. New Delhi. Kumar Publishing House 2004; $49,545$.

[5] Galleges De Hernandez et. al., WHO study group on Community Health Workers. Geneva. Dec. 87 ; 4- 13.

[6] Kulkarni A.P., Baride. Textbook of community Medicine. $2^{\text {nd }}$ education year 442 publication.

[7] Department of Community and Social Medicine. Mac. Sot Gen. Hospital Thailand. South East. Asian. J Trop. Med Public Health. 1992. Jun.: 23 (2): 207

[8] Sebastian Ousepparampil. Strengthening the health workforce. Health Action 2006 Apr. 19 (4): 1 - 14.

[9] Barzgar MA, Shaikh MR and Bile MK. Female health workers boost primary are world health forum $1997 ; 18: 202-9$. 